and of education, with a tendency to favour the former over the latter when the induction day is local. To some extent we have succeeded in circumventing this conflict in SW Thames by combining local induction days with a regional induction for trainees new to the rotation. The regional induction day is organised to address educational issues, including psychotherapy and research opportunities. This has the additional advantage of engendering a sense of cohesion in the rotation as a whole.

My suggestion is that the practical difficulties of organising regional induction days are eventually justified by sustaining the morale and quality of a rotation, freeing the local hospitals to concentrate on service provision.

JOHN FARNILL MORGAN, Registrar and Chairman of SW Thames Junior Doctors Committee, Epsom District Hospital, Epsom, Surrey

\section{Supervision of trainees}

Sir: The regular individual supervision of trainees by their educational supervisors is a requirement of the College for a training scheme to retain approval. The 'Statement of training schemes for general professional training for the MRCPsych' (Psychiatric Bulletin, 1994, 18, 514-522) lays down clearly what the College requires but with respect to the issue of individual supervision the document could be interpreted in more than one way. This has important implications as failure to comply with the standards laid down in the statement could lead to approval for a scheme being withdrawn.

In paragraph 5 (a) of the 'Organisation' section it is stated that "It is required that an hour a week is spent by the educational supervisor with the trainee on his or her own - not for the purposes of carrying out psychiatric management". This seems straightforward and is the standard that most educational supervisors try to attain. In paragraph 1 under 'Types of teaching', however, regular direct supervision can be individually or in small groups, suggesting that this must be describing supervision additional to the required individual hour. That the rest of this paragraph describes the need for clinical supervision of the management of new and follow-up outpatients reinforces the impression that this is not the supervision described earlier in the document. It is the presence in this paragraph of the statement "Such supervision should occur at least weekly for one hour", that gives rise to the confusion.

Some College officials (including the members of the panel on a recent College approval visit) seem to interpret this document to mean that educational supervisors should be setting aside two hours per week to spend individually with their trainee, one hour for case management issues, the other hour expressly for any other purpose. Others say that it is the hour for non-management issues that is mandatory, and that while adequate supervision of the trainee's management of patients is essential and should include presentation of cases to the supervisor, supervisors are not required to set aside a further hour each week purely for this purpose. I hope that this can be clarified before supervisors who conscientiously provide an hour of supervision per week find themselves penalised for not providing two, or alternatively unnecessary disruption is caused to clinical service provision throughout the country as supervisors rearrange their working weeks to provide an extra timetabled hour of supervision in the mistaken belief that this is what the College requires.

J. J. ClARKE, Thorneywood Child and Adolescent Psychiatry Unit, Porchester Road, Nottingham NG3 6LF

Sir: I am grateful to Dr Clarke for bringing to my attention a possible ambiguity in the Approval Statement of Training Schemes from the Court of Electors.

Dr Clarke is, of course, correct in his opinion that the Court is concerned to ensure that each trainee has one hour 'face-to-face' general supervision with an educational supervisor (consultant) each week. Such supervision is independent of, and additional to, the clinical supervision which the educational supervisor is also expected to provide with regard to the management of individual patients. Such clinical supervision may occur within a multidisciplinary team, ward round setting or general practice health clinic.

The content of the weekly general supervision, as implied within the Statement, does include career advice, assistance with basic interviewing skills, and feedback about 